2. Peter Reynolds, A sister for The Mathematical Gazette, Math. Gaz. 80 (March 1996), pp. 33-34.

3. Editorial, Mathematics in School, 1(1), (November 1971), p. 1.

4. Michael H. Price, Mathematics for the multitude? A history of The Mathematical Association, Mathematical Association (1994).

5. P. Reynolds, Hand calculators: a 1969 report on their use in schools, Math. Gaz. 54 (February 1970) pp. 41-44.

6. P. Reynolds, That impostor 1.4142136, Math. Gaz. 79 (November 1995) pp. 533 - 536.

7. Margaret Brown, Private cominunication (December 2000).

STEVE ABBOTT

91 High Koad West, Felixstowe IP11 9AB

\title{
Memories of Peter Reynolds
}

I first came across Peter in the 1960s. Both he and his wife Marion were regular attenders at mathematical conferences particularly those of the MA and ICME.

We worked together closely on the Mathematical Association Diploma Board in the 1970s and early 1980s. Peter, as chairman, guided the work of the Board with care, patience and skill - at one time some 60 to 70 colleges and other institutions were offering the Association's diploma and the organisation of visits and validation required a huge amount hard work and effort. Peter was always proud of the success of this diploma.

After his 'retirement' we worked together on the Nuffield National Curriculum Mathematics Project, with Peter as director, for 5 years in the 1990s. The project experienced the frustrations of much political meddling with the curriculum and often, as fast as material was produced, the curriculum was changed!

After serving the Mathematical Association in many capacities (including that of President) for some 35 years, Peter was still, as a member of Council, more than willing to take on tasks that others shunned - he spent much time after his presidency guiding the Professional Development Committee.

He was always prepared to support both his subject and teachers against bureaucratic interference and was justly proud of his work on the Cockcroft committee and the National Curriculum Working Party.

Aside from mathematics, Peter and Marion were close personal friends and my wife and I enjoyed many evenings of good food, drink and conversation with them. Peter was never happier than when he was sitting in the sun watching a cricket match unfold; we spent many pleasant hours together at grounds in Chelmsford, Bath, Taunton and elsewhere. He will be much missed both as a friend and as a servant to mathematical education. 